\title{
Impaired renal function and associated risk factors in newly diagnosed HIV-infected adults in Gulu Hospital, Northern Uganda
}

\author{
Pancras Odongo ${ }^{1}$, Ronald Wanyama ${ }^{1 *}$, James Henry Obol ${ }^{1}$, Paska Apiyo ${ }^{2}$ and Pauline Byakika-Kibwika ${ }^{3}$
}

\begin{abstract}
Background: Screening for renal diseases should be performed at the time of diagnosis of human immunodeficiency virus (HIV) infection. Despite the high prevalence of HIV/AIDS in Northern Uganda, little is known about the status of renal function and its correlates in the newly diagnosed HIV-infected individuals in this resource limited region. We aimed to determine the status of renal function and factors associated with impaired renal function in newly diagnosed HIV-infected adults in Northern Uganda.
\end{abstract}

Methods: This was a seven month cross-sectional hospital-based study, involving newly diagnosed HIV-infected patients, 18 years and older. Patients with history of diabetes mellitus, hypertension and renal disease were excluded. Estimated glomerular filtration rate (eGFR) was calculated using Chronic Kidney Disease Epidemiology Collaboration (CKD-EPI) formula (Table one). Factors associated with impaired renal function (eGFR $<60 \mathrm{ml} / \mathrm{min} / 1.73 \mathrm{~m}^{2}$ ) were thus sought.

Results: We enrolled 361 participants (230,63.7\% female) with Mean \pm standard deviation age of $31.4 \pm 9.5$ years. 52, (14.4\%) had impaired renal function (eGFR $<60 \mathrm{~mL} / \mathrm{min} / 1.73 \mathrm{~m}^{2}$ ) and of this $37(71.2 \%)$ moderate renal impairment (eGFR 30-59.9 mL/min/1.73 m²) while 15 (28.8\%) had severe renal impairment (eGFR $<30 \mathrm{~mL} / \mathrm{min} / 1.73 \mathrm{~m}^{2}$ ). Proteinuria was recorded in 189 (52.4\%) participants. Of these, 154 (81.5\%) had mild (1+) while 8 (4.2\%) had severe (3+) proteinuria. Using logistic regression, age, CD4 cell count, and proteinuria were significantly associated with impaired renal function; age $>34$ years (OR 2.8, 95\% Cl $1.3-5.9 ; P=0.009), \mathrm{CD} 4$ count $<350 \mathrm{cells} / \mathrm{\mu L}(\mathrm{OR} 2.4,95 \% \mathrm{Cl} 1.0-4.7 ; P=0.039)$ and proteinuria (OR 9.6, 95\% Cl 5.2-17.9; $P<0.001$ ).

Conclusion: The prevalence of impaired renal function was high in new HIV-infected individuals in this region with limited resources. So, screening for renal disease in HIV is recommended at the time of HIV diagnosis.

Keywords: Renal function, Kidney disease, HIV, Gulu, Northern Uganda

\section{Background}

Human immunodeficiency Virus (HIV) is a leading cause of morbidity and mortality especially in subSaharan Africa. The HIV-infected individuals may suffer both HIV-associated and non HIV-associated kidney disease which may worsen their prognosis. Non HIVassociated kidney disease may follow hypertension, diabetes mellitus, infections and many other causes while HIV-associated kidney disease may occur as HIVassociated nephropathy, nephropathy due to opportunistic

\footnotetext{
* Correspondence: rwanyama@gmail.com

${ }^{1}$ Faculty of Medicine, Gulu University, P.O. Box 166, Gulu, Uganda

Full list of author information is available at the end of the article
}

infections, immune complex mediated glomerulonephritis, thrombotic microangiopathy, interstitial nephritis and various electrolyte disturbances among others [1-4]. Globally, the prevalence of renal disease among the HIVinfected adult population has been estimated to range between 5 and 30\% [5-7]. In sub-Saharan Africa, the prevalence is estimated between 6 and 48.5\% [6,8]. In Uganda, the incidence of renal disease in HIV-infected persons is expected to increase, even though highly effective antiretroviral therapy is increasingly available.

Screening for renal disease is recommended for all HIV-infected individuals at diagnosis of the infection and at initiation of antiretroviral therapy (ART) [9]. If 
not detected and managed timely and appropriately, AIDS-associated renal disease may progress to end-stage renal disease (ESRD) requiring renal replacement therapy [10]. Renal dysfunction at the time of initiation of ART or during ART is associated with complications such as faster progression to AIDS, high blood pressure, bone demineralization and anemia [10] which present significant challenges to HIV management especially in resource limited settings. Early initiation of ART may improve the treatment outcomes of individuals with HIV-associated kidney disease [11].

Although current guidelines recommend determination of renal function prior to ART initiation, this is often not performed due to resource constraints in many areas in sub-Saharan Africa. Moreover, there is enormous evidence that HIV-infected patients receiving ART are surviving longer. Currently recommended ART regimens include 2 nucleoside/nucleotide reverse transcriptase inhibitors (NRTIs) plus a nonnucleoside reverse transcriptase inhibitor as first line therapy and 2 NRTIs plus a protease inhibitor as second line therapy. Some of these drugs are known to cause kidney toxicity such as tenofovir, indinavir and atazanavir, underscoring the need to screen and monitor HIV-infected patients for kidney disease pre and during ART. Several studies have demonstrated ART associated renal toxicity with underlying risk factors such as pre-existing renal disease, untreated and advanced HIV disease, administration of other renal toxic drugs, female gender and older age, longer duration on ART, dehydration, opportunistic infections and African-American ethnicity [12].

Despite the high prevalence of HIV/AIDS in Northern Uganda, little is known about the status of renal function in the HIV-infected individuals in this resource limited region. Renal function pre-ART and during ART is not routinely performed. The cost of chronic renal replacement therapy is exorbitant for majority of people in this setting. An emphasis should be placed on early detection and management of HIV-infected individuals. Interventions such as avoidance of nephrotoxic drugs and substances, blood pressure and glucose control can be used to slow progression and prevent development of end stage renal disease. We aimed to determine the status of renal function and factors associated with impaired function in newly diagnosed HIV-infected adults in Gulu Regional Referral Hospital in Northern Uganda.

\section{Methods}

\section{Study site}

This study was conducted at the infectious diseases clinic of Gulu Regional Referral Hospital between August 2013 and February 2014. The hospital is located in Gulu Municipality in Northern Uganda and supported by the Ministry of Health. All services are provided free of charge to the public including HIV care and treatment.

\section{Ethical considerations}

The study was approved by Gulu University Faculty of Medicine Research and Ethics Review Committee and cleared by Uganda National Council of Science and Technology. All participants provided written informed consent at enrollment. The consent process was administered in the local language.

\section{Study design and population}

We conducted a cross sectional study among newly diagnosed HIV infected adults aged 18 years and above who were not yet receiving cotrimoxazole prophylaxis and/or ART. We excluded patients with conditions known to be associated with kidney abnormalities such as acute infections, pregnancy, previously diagnosed systemic hypertension, diabetes, and known renal disease. Based on these criteria, a total of 23 patients were excluded from this study (4 were hypertensive, 4 had diabetes mellitus type II, 6 had pyrexia (body temperature $>38^{\circ} \mathrm{C}$ ), 8 were pregnant and 1 had renal disease). HIV testing was performed using Determine strips (Alere Medical Co, Japan) and confirmed by Stat-pak (Chembio diagnostic system Inc, New York) or Unigold kits. Participants were enrolled consecutively till the required sample size of 365 was achieved.

\section{Study procedures}

Patients who fulfilled the study criteria were enrolled consecutively and interviewed for demographic, social and behavioral data. Medical history was collected and complete physical examination performed. Nutritional status was assessed using body mass index (BMI) which was obtained using the formula body weight in kilograms divided by height squared in meters. Following aseptic technique, $5 \mathrm{~mL}$ of venous blood was drawn from each participant into a syringe for renal function tests, and CD4 count. About $1.5 \mathrm{~mL}$ of blood for CD4 count was transferred into purple top vacutainers and blood for renal function tests was transferred into orange top vacutainers with a gel separator. Serum creatinine and urea were determined using an automated clinical chemistry analyzer (Humastar 180, Human diagnostics). Estimated glomerular filtration rate (eGFR) was calculated using Chronic Kidney Disease Epidemiology Collaboration (CKD-EPI) formula (Table 1) which studies have shown to be comparable to modification of diet in renal disease (MDRD) for estimating estimated glomerular filtration rate (eGFR) in HIV-infected patients [13]. 
Table 1 CKD EPI equation for estimating GFR expressed for black race, sex and serum creatinine in $\mathrm{mg} / \mathrm{dL}$

\begin{tabular}{lll}
\hline Sex & $\begin{array}{l}\text { Serum creatinine, } \\
\mathbf{S}_{\mathbf{c r}}(\mathbf{m g} / \mathbf{d L})\end{array}$ & Equation (age in years for $\geq 18)$ \\
\hline Female & $\leq 0.7$ & $\mathrm{GFR}=166 \times\left(\mathrm{S}_{\mathrm{cr}} / 0.7\right)^{-0.329} \times(0.993)^{\mathrm{Age}}$ \\
Female & $>0.7$ & $\mathrm{GFR}=166 \times\left(\mathrm{S}_{\mathrm{cr}} / 0.7\right)^{-1.209} \times(0.993)^{\text {Age }}$ \\
Male & $\leq 0.9$ & $\mathrm{GFR}=163 \times\left(\mathrm{S}_{\mathrm{cr}} / 0.9\right)^{-0.411} \times(0.993)^{\text {Age }}$ \\
Male & $>0.9$ & $\mathrm{GFR}=163 \times\left(\mathrm{S}_{\mathrm{cr}} / 0.9\right)^{-1.209} \times(0.993)^{\text {Age }}$ \\
\hline
\end{tabular}

We used clinical guidelines from the US National Kidney Foundation's Kidney Disease Outcome Quality Initiative (K/DOQI) to categorize renal insufficiency to grade renal impairment [14]. Creatinine clearance of $>90 \mathrm{~mL} / \mathrm{min} / 1.73 \mathrm{~m}^{2}$ was considered normal; creatinine clearance of 60 to $89.9 \mathrm{~mL} / \mathrm{min} / 1.73 \mathrm{~m}^{2}$ (K/DOQI stage 2) was categorized as mild renal insufficiency; 30 to $59.9 \mathrm{~mL} / \mathrm{min} / 1.73 \mathrm{~m}^{2}$ as moderate insufficiency (K/DOQI stage 3 ); and $<30 \mathrm{~mL} / \mathrm{min} / 1.73 \mathrm{~m}^{2}$ as severe insufficiency (K/DOQI stages 4 and 5). For the purposes of this study, eGFR of below $60 \mathrm{~mL} / \mathrm{min} /$ $1.73 \mathrm{~m}^{2}$ was used as the cutoff point for impaired renal function [15]. The CD4 cell count was measured using a Facs Calibur CD4 machine. Each participant provided a midstream urine sample for dipstick analysis. The urine samples were analyzed immediately using a dipstick (strips by Alecon cedex, France). Proteinuria on dipstick was reported as negative, $1+(30 \mathrm{mg} / \mathrm{dL}), 2+(100 \mathrm{mg} / \mathrm{dL})$, or $3+(300 \mathrm{mg} / \mathrm{dL})[16]$.

\section{Statistical analysis}

Data were analyzed using the Statistical Package for the Social Sciences version 16. Social, demographic and baseline clinical and laboratory parameters were summarized into frequencies, Means \pm standard deviation (SD). Tests for the significance of association were made using the Pearson chi-square $\left(\chi^{2}\right)$ test for categorical variables and independent sample $t$ test for continuous variables. Risk factors for renal impairment were determined with logistic regression. The outcome variable was impaired renal function $\left(e G F R<60 \mathrm{~mL} / \mathrm{min} / 1.73 \mathrm{~m}^{2}\right)$. The covariates were age, proteinuria, CD4 cell count and serum urea. Risk factors for impaired renal function with $P$ values $<0.05$ during univariate analysis were considered for multivariate analysis using logistic regression to determine independent risk factors of impaired renal function.

\section{Results}

Table 2 summarizes the overall socio-demographic characteristics of the study participants. The same table also shows comparison of these characteristics between the patients with and without renal impairment. Three hundred sixty five (365) ART naïve HIV-infected patients were enrolled into the study. Four patients had incomplete records (age, serum creatinine or gender which we needed to calculate eGFR) and were excluded from the analysis. However, data were missing on occupation for 2 subjects. Of the 361 patients analyzed, $63.7 \%(230 / 361)$ were female. The majority, $90.4 \%$ $(327 / 361)$ of the patients were in early stages of HIV infection (WHO clinical stages I and II). The majority of the patients were non smokers and were not taking alcohol $86.1 \%(311 / 361)$ and $74.9 \%(274 / 361)$ respectively. Very few patients, 5.3\% (19/361) had attained education beyond secondary level as the majority had only attained primary education. There were no differences in the socio-demographic categorical variables between the participants with impaired renal function and those with normal renal function as shown in Table 2.

Renal function, immunological status and nutrition status A summary of participants' renal function, immunological status and nutritional status are shown in Table 3. Of the 361 participants, 36.8\% (133/361) had impaired renal function. Of these, $(81,60.9 \%)$ had mild renal impairment (eGFR 60-89.9 $\mathrm{mL} / \mathrm{min} / 1.73 \mathrm{~m}^{2}$ ), 37, 27.8\% had moderate impairment (eGFR $30-59.9 \mathrm{~mL} / \mathrm{min} / 1.73 \mathrm{~m}^{2}$ ) while $15,11.3 \%$ had severe impairment (eGFR $<30 \mathrm{~mL} /$ $\left.\min / 1.73 \mathrm{~m}^{2}\right)$. Low CD4 cell count $(\mathrm{CD} 4<350$ cells $/ \mu \mathrm{L})$ was recorded in $38.2 \%(126 / 361)$ of the participants while $33 \%$ (119/361) had chronic protein-energy under-nutrition indicated by body mass index (BMI $<18.5 \mathrm{~kg} / \mathrm{m}^{2}$ ). Proteinuria was recorded in $52.4 \%(189 / 361)$ participants. Of those with proteinuria, majority $81.5 \%(154 / 189)$ had mild $(1+)$ while $4.2 \%(8 / 189)$ had severe $(3+)$ proteinuria.

Table 4 shows the Mean \pm SD of selected variables and also comparison of means of patients with impaired renal function and those with normal renal function. The Mean \pm SD age of the enrolled participants was $31.4 \pm 9.5$ years. The participants' Mean \pm SD weight and BMI were $55.0 \pm 8.8 \mathrm{~kg}$ and $19.80 \pm 2.8 \mathrm{~kg} / \mathrm{m}^{2}$ respectively. The median Mean \pm SD height CD4 count, eGFR, urea and creatinine were $167.9 \pm 7.7 \mathrm{~cm}, 450.0 \pm 130.2$ cells $/ \mu \mathrm{L}, 104.3 \pm 45.8 \mathrm{~mL} / \mathrm{min} / 1.73 \mathrm{~m}^{2}, 23.5 \pm 2.8 \mathrm{mg} / \mathrm{dL}$ and $1.2 \pm 0.6 \mathrm{mg} / \mathrm{dL}$ respectively.

The mean age of the patients with decreased eGFR was 35.0 years and was significantly higher than 30.67 years for the others, $P=0.001$. The mean CD4 count $(334.27$ cells $/ \mu \mathrm{L})$ of the patients with decreased eGFR was significantly lower than that of others 495.28 cells $/ \mu \mathrm{L}, P<0.001$. The mean serum creatinine of patients with decreased eGFR was $2.76 \mathrm{mg} / \mathrm{dl}$ and was significantly higher than $0.86 \mathrm{mg} / \mathrm{dl}$ for the others, $P<0.001$. There was no statistical difference in the BMI, weight, height of patients with and without renal impairment (Table 4). 
Table 2 General characteristics of the studied population

\begin{tabular}{|c|c|c|c|c|}
\hline Variable & Decreased eGFR $<60 \mathrm{~mL} / \mathrm{min} / 1.73 \mathrm{~m}^{2}(\%)$ & Normal eGFR $\geq 60 \mathrm{~mL} / \mathrm{min} / 1.73 \mathrm{~m}^{2}(\%)$ & Total number (\%) & $P$ value \\
\hline Sex & & & & $0.153^{*}$ \\
\hline Female & $38(16.5)$ & $192(83.5)$ & $230(63.7)$ & \\
\hline Male & $14(10.7)$ & $117(89.3)$ & $131(36.3)$ & \\
\hline WHO clinical stage & & & & $0.094^{*}$ \\
\hline Early stage (I \& II) & $44(13.5)$ & $283(86.5)$ & $327(90.6)$ & \\
\hline Advanced stage (III \& IV) & $8(23.5)$ & $26(76.5)$ & $34(9.4)$ & \\
\hline Occupation & & & & $0.442^{*}$ \\
\hline House wife/no job & $20(17.1)$ & $97(82.9)$ & $117(32.6)$ & \\
\hline Peasant farmer & $16(11.3)$ & $126(88.7)$ & $142(39.6)$ & \\
\hline Employed & $15(15.0)$ & $85(85.0)$ & $100(27.8)$ & \\
\hline Residence & & & & $0.453^{*}$ \\
\hline Rural & $12(11.4)$ & $93(88.6)$ & $105(29.1)$ & \\
\hline Urban & $40(15.6)$ & $216(84.4)$ & $256(70.9)$ & \\
\hline Smoking & & & & $0.686^{*}$ \\
\hline Yes & $7(14.0)$ & $43(86.0)$ & $50(13.9)$ & \\
\hline No & $42(13.5)$ & $269(86.5)$ & $311(86.1)$ & \\
\hline Building type & & & & $0.836^{*}$ \\
\hline Permanent & $6(13.6)$ & $38(86.4)$ & $44(12.2)$ & \\
\hline Temporary & $46(14.5)$ & $271(85.5)$ & $317(87.8)$ & \\
\hline Alcohol & & & & $0.872^{*}$ \\
\hline Yes & $14(16.1)$ & $73(83.9)$ & $87(24.1)$ & \\
\hline No & $38(13.9)$ & $236(86.1)$ & $274(75.9)$ & \\
\hline Marital status & & & & $0.791^{*}$ \\
\hline Married & $24(12.7)$ & $165(87.3)$ & 179 (49.6) & \\
\hline Single & $7(13.0)$ & $47(87.0)$ & $54(14.9)$ & \\
\hline Widowed/Divorced & $21(16.4)$ & $107(83.6)$ & $128(35.5)$ & \\
\hline Water source & & & & $0.839^{*}$ \\
\hline Hygienic & $44(17.5)$ & $208(82.5)$ & $252(69.8)$ & \\
\hline Unhygienic & $20(18.3)$ & $89(81.7)$ & $109(30.2)$ & \\
\hline Education level & & & & $0.749^{*}$ \\
\hline Low (primary \& uneducated) & $32(12.5)$ & $219(87.5)$ & $251(69.5)$ & \\
\hline Medium (secondary) & $16(17.6)$ & $75(82.4)$ & $91(25.2)$ & \\
\hline High (above secondary) & $4(21)$ & $15(79)$ & $19(5.3)$ & \\
\hline Household income/month & & & & $0.207^{*}$ \\
\hline Low income $(<\$ 160)$ & $36(12.6)$ & $250(87.4)$ & $286(79.7)$ & \\
\hline Medium income (\$160-400) & $13(21.3)$ & $48(78.7)$ & $61(17.0)$ & \\
\hline High income (>\$400) & $3(25)$ & $9(75)$ & $12(3.3)$ & \\
\hline
\end{tabular}

${ }^{*} \boldsymbol{P}$ valve for the Pearson chi-square.

Factors associated with renal impairment

For logistic regression, moderate renal impairment was used as the outcome variable. The covariates were age, CD4 count, urea, and proteinuria. Age (odds ratio [OR] 2.8, 95\% confidence interval $[\mathrm{CI}] 1.3-5.9 ; P=0.009)$, CD4 count (OR 2.4, 95\% CI 1.0-4.7; $P<0.039$ ) and proteinuria (OR 9.6, 95\% CI 5.2-17.9; $P<0.001$ ) were significantly associated with the outcome (Table 5). However, urea was not independently associated with renal impairment (OR 1.9, 95\% CI 0.9-4.0; $P<0.11$ ).

\section{Discussion}

We aimed to determine renal function status and factors associated with impaired function in newly diagnosed 
Table 3 Participants' renal function, CD4 count, nutritional status and stages of renal damage

\begin{tabular}{ll}
\hline Variable & Number (\%) \\
\hline Estimated GFR & \\
Normal GFR $\geq 60 \mathrm{~mL} / \mathrm{min} / 1.73 \mathrm{~m}^{2}$ & $309(85.6)$ \\
Reduced GFR $<60 \mathrm{~mL} / \mathrm{min} / 1.73 \mathrm{~m}^{2}$ & $52(14.4)$ \\
Stage of CRD $\left(\mathrm{mL} / \mathrm{min} / 1.73 \mathrm{~m}^{2}\right)$ & \\
No damage $>90$ & $228(63.2)$ \\
Stage II $60-89.9$ & $81(22.4)$ \\
Stage III $30-59.9$ & $37(10.2)$ \\
Stage IV $15-29.9$ & $9(2.5)$ \\
Stage V $<15$ & $6(1.7)$ \\
CD4 cell count (cell/ $/ \mathrm{LL})$ & \\
High CD4 $\geq 350$ & $227(62.8)$ \\
Low CD4<350 & $126(38.2)^{* *}$ \\
Body mass index (kg/m $\left.\mathbf{m}^{2}\right)$ & \\
$<18.5$ & $119(33)$ \\
$\geq 18.5$ & $242(67)$ \\
Urine protein & \\
Negative & $172(47.6)$ \\
$+(30 \mathrm{mg} / \mathrm{dL})$ & $154(42.7)$ \\
$++(100 \mathrm{mg} / \mathrm{dL})$ & $27(7.5)$ \\
$+++(300 \mathrm{mg} / \mathrm{dL})$ & $8(2.2)$ \\
\hline
\end{tabular}

**Percentage of participants eligible for ART.

HIV-infected adults in Gulu Regional Referral Hospital in Northern Uganda. Defining renal impairment as eGFR $<90 \mathrm{~mL} / \mathrm{min} / 1.73 \mathrm{~m}^{2}$, we found a high prevalence of renal insufficiency of $36.9 \%$. This finding is similar to that from a study done in Zambia where renal impairment was found in $33.5 \%$ of the HIVinfected patients initiating ART [17], and from studies in Nigeria where prevalence was $38 \%$ and $39 \%[8,18]$ who used the same cut off of eGFR $<90 \mathrm{~mL} / \mathrm{min} / 1.73 \mathrm{~m}^{2}$ to define renal impairment. However, both the Zambian and Nigerian studies used Cockroft and Gault formula for calculating eGFR. When renal impairment was defined as eGFR $<60 \mathrm{~mL} / \mathrm{min} / 1.73 \mathrm{~m}^{2}, 14.4 \%$ of our newly diagnosed HIV-infected participants had renal dysfunction. Our finding compares very well with the study done in Kenya by Kaloustian et al. [19] which recorded a prevalence of $11.5 \%$ using the same definition with MDRD formula which compares very well with CKDEPI. However, our finding is lower than the recent finding of $24 \%$ in Nigeria\% [18] and higher than findings by Wyatt et al. [20] in Rwanda and by Ekat et al. [21] in Brazaville, Congo of $2.7 \%$ and $7.9 \%$ respectively. The low prevalence of renal impairment in Wyatt et al. study used a population of only HIV positive women while our study included both men and women. Our finding of $14.4 \%$ is almost less than half the finding of Onodugo et al. possibly of two reasons. First, most (almost $40 \%$ ) of the patients with eGFR $<60 \mathrm{~mL} / \mathrm{min} / 1.73 \mathrm{~m}^{2}$ in the Nigerian study were in chronic kidney disease stage 5 where as only $11.5 \%$ of our participants with eGFR $<60 \mathrm{~mL} / \mathrm{min} /$ $1.73 \mathrm{~m}^{2}$ were in chronic kidney disease stage 5 . It could also be because of the different method used to estimate the GFR in this study. Our present prevalence of $14.4 \%$ is almost twice that found in Brazaville yet majority (90.6\%) of our participants were in early disease stages (I \& II) of HIV infection and majority (70.8\%) of the participants in Ekat et al. study were in advanced disease stages (III \& IV) [21]. The disparity in prevalence between studies seems to be explained mainly by the definitions of the impaired renal function and characteristics of studied patients. There is a chance that the prevalence of renal failure would have been higher than this if we had more of our participants in advanced stages of HIV-infection since the risk of failure increases with advancing clinical stage [22-24].

There was high prevalence of proteinuria among our study participants $(\mathrm{n}=189,52.4 \%)$, similar to findings from Nigeria [8]. This finding is higher than that by Chioma et al. [25] who found prevalence of proteinuria of $38.1 \%$. The difference could be due to the fact that we used one spot urine sample while Chioma et al. used two serial urine samples four weeks apart to diagnose proteinuria. Longo et al. [26] found a lower prevalence of proteinuria of $20.5 \%$ and Kaloustian et al. found much lower prevalence of $6.2 \%$ [19]. From our study we observed that proteinuria (3+) detects renal impairment in $100 \%$ of the HIVinfected adults who are ART naïve in this resource limited region (Table 3 ).

Notable in this study is the very high prevalence of mild renal impairment in the study population. Although dose adjustment of medication or additional monitoring may not be necessary in HIV patients with mild renal impairment, and they may improve on antiretroviral therapy, it is important that such patients be identified [14,27]. Mild renal insufficiency has been reported to be associated with increased risk of mortality [28].

For resource limited settings, screening for renal impairment could be limited to individuals who do not immediately qualify for ART. This will detect those that will commence ART due to renal impairment. This because studies have shown that in settings where renal insufficiency is diagnosed but the etiology is unknown; provision of ART in itself improves renal function [29]. This is very important considering the rapid and severe clinical course associated with HIVAN which can improve, with preservation of long-term renal function, by a trial of empiric ART [30]. 
Table 4 Characteristics of study participants at screening by degree of renal impairment

\begin{tabular}{|c|c|c|c|c|}
\hline \multirow[t]{2}{*}{ Variable, $\mathrm{N}=361$} & \multicolumn{2}{|l|}{ Mean \pm SD of variables } & \multirow[t]{2}{*}{ Mean \pm SD } & \multirow[t]{2}{*}{$P$ value } \\
\hline & Decreased eGFR $<60 \mathrm{~mL} / \mathrm{min} / 1.73 \mathrm{~m}^{2}$ & Normal eGFR $\geq 60 \mathrm{~mL} / \mathrm{min} / 1.73 \mathrm{~m}^{2}$ & & \\
\hline Age (years) & $35.1 \pm 8.6$ & $30.7 \pm 9.6$ & $31.4 \pm 9.5$ & $0.001^{* *}$ \\
\hline Height (cm) & $168.3 \pm 7.7$ & $167.6 \pm 7.5$ & $167.9 \pm 7.7$ & $0.508^{* *}$ \\
\hline Weight (kg) & $56.8 \pm 9.3$ & $56.4 \pm 8.7$ & $55.0 \pm 8.8$ & $0.761^{* *}$ \\
\hline BMI $\left(\mathrm{kg} / \mathrm{m}^{2}\right)$ & $19.9 \pm 3.1$ & $20.0 \pm 2.7$ & $19.80 \pm 2.8$ & $0.626^{* *}$ \\
\hline CD4 count (cells/ $\mu \mathrm{L}$ ) & $334.3 \pm 9.7$ & $495.3 \pm 130.5$ & $450.0 \pm 130.2$ & $<0.001^{* *}$ \\
\hline eGFR $\left(\mathrm{mL} / \mathrm{min} / 1.73 \mathrm{~m}^{2}\right)$ & $40.1 \pm 15.9$ & $125.2 \pm 37.5$ & $104.3 \pm 45.8$ & $<0.001^{* *}$ \\
\hline Urea (mg/dL) & $30.1 \pm 3.8$ & $22.1 \pm 2.5$ & $23.5 \pm 2.8$ & $0.039^{* *}$ \\
\hline Creatinine (mg/dL) & $2.76 \pm 1.2$ & $0.86 \pm 0.2$ & $1.2 \pm 0.6$ & $<0.001^{* *}$ \\
\hline
\end{tabular}

**P valve for the independent sample $t$ test.

Studies done in Africa have found renal insufficiency to be associated with increased risk for death $[17,19]$. We found a significant association between estimated GFR and CD4 cell counts implying that individuals with advanced immune suppression as measured by the CD4 count had more advanced renal impairment as measured by the GFR. Our finding is similar to findings in South Africa, Malawi and India [22-24] where low CD4 cell count below 350cells/ $\mu \mathrm{L}$ was an independent predictor for impaired renal function. However, Wyatt et al. did not find a significant association between these two parameters [20]. This high prevalence of renal impairment has significant implications for HIV treatment in this area where tenofovir is the preferred NRTI for first-line ART. Guidelines recommend tenofovir dose adjustments to prevent further renal damage when creatinine clearance is below $50 \mathrm{~mL} / \mathrm{min}[31,32]$. Approximately $12 \%$ of participants in our study would have required tenofovir dose adjustments and nearly $3 \%$ would have benefited from serial creatinine monitoring if they were to initiate tenofovir-based ART. While a strategy of routine screening will increase costs of HIV care in resource constrained settings, it must be balanced against the risk of worsening renal impairment following ART initiation regardless of renal function consideration. Similar concerns should be raised if HIV-infected individuals are to receive other ART drugs with known renal toxicities, such as indinavir and atazanavir.

Table 5 Factors associated with impaired renal function

\begin{tabular}{llll}
\hline Covariate $(\mathbf{N}=\mathbf{3 6 1})$ & $\boldsymbol{P}$ value & Odds ratio & $\begin{array}{l}\mathbf{9 5 \%} \text { Confidence } \\
\text { Interval }\end{array}$ \\
\hline Proteinuria & $<0.001$ & 9.6 & $5.2-17.9$ \\
Age $>34$ years & 0.009 & 2.8 & $1.3-5.9$ \\
CD4 count $<350$ cells/ $\mathrm{LL}$ & 0.039 & 2.2 & $1.0-4.7$ \\
Serum urea $>20 \mathrm{mg} / \mathrm{dl}$ & 0.11 & 1.9 & $0.9-4.0$ \\
\hline
\end{tabular}

Variable(s) entered on step 1: Protenuria, Age, CD4 count, serum urea.
Majority of our study participants were categorised as WHO clinical stage I and II and had CD4 count greater than 350 cells $/ \mu \mathrm{L}$ compared to findings in some studies where ART naïve newly diagnosed HIV-infected patients were found with very low CD4 counts $[6,15]$ signifying advanced immune suppression at start of HIV care. For example in Ekat et al. [6], study, 70.8\% of HIV-infected adults in advanced disease stage (III \& IV) while in our study only $9.4 \%$ of the participants in advanced disease stage. Our findings imply that adults in this region possibly seek HIV testing and care services early compared to other settings. Uganda has been implementing the routine counseling and testing program for more than five years. All individuals presenting to a health facility are offered HIV counseling and testing. This could also possibly explain the early HIV diagnosis in this population. More than one third of participants were eligible for ART according to national guidelines at the time the study was conducted which has significant implications for ART provision in Uganda.

Our study had some limitations; both creatinine and proteinuria were measured at a single point in time; therefore, we may have included short term, reversible causes of renal impairment. We did not assess for microalbuminuria although it has been shown to be the earliest marker of renal disease. Furthermore, estimation of eGFR and creatinine clearance is affected by medications, diet, protein intake, circulating cortisol levels, and muscle wasting, factors that this study did not explore.

\section{Conclusions}

The prevalence of impaired renal function was high in HIV-infected individuals in Northern Uganda, a region which is limited resources. So, screening for renal disease in HIV is recommended at the time of HIV diagnosis. We also recommend use of urine dipstick to detect proteinuria which is a good proxy of renal impairment especially moderate $(2+)$ and severe $(3+)$. 


\section{Abbreviations}

AIDS: Acquired Immunodeficiency Syndrome; ART: Antiretroviral Therapy; BMI: Body Mass Index; CKD-EPI: Chronic Kidney Disease Epidemiology Collaboration; eGFR: Estimated glomerular filtration rate; GFR: Glomerular filtration rate; HIV: Human immunodeficiency Virus; MDRD: Modified Diet in Renal Disease; NRTIs: Nucleoside/nucleotide reverse transcriptase inhibitors; SD: Standard Deviation.

\section{Competing interests}

The authors declare that they have no competing interests.

\section{Authors' contributions}

$\mathrm{PO}$ conceived the idea, RW, PO, JHO, PA and PBK, designed the study. RW, PO, and PBK participated in data collection. RW analyzed the data. RW, PO, and PBK interpreted the data. RW, PO, and PBK drafted the first version and all authors reviewed the manuscript and approved the final version of the manuscript.

\section{Acknowledgements}

We are thankful to the study participants. We thank Gulu University Faculty of Medicine and Infectious Diseases Clinic of Gulu Hospital for administrative support. We are also thankful to the following staff of Infectious diseases clinic of Gulu Hospital, Santa Olal, Justine Gumukura, Joseph Mwol and Tophic Mukidadi, who helped with collection of data.

\section{Funding}

The work was supported by Training Health Researchers into Vocational Excellence in East Africa (THRIVE), Grant Number 087540, funded by the Wellcome Trust.

\section{Author details}

${ }^{1}$ Faculty of Medicine, Gulu University, P.O. Box 166, Gulu, Uganda. Infectious Diseases Clinic, Gulu Regional Referral Hospital, P.O. Box 160, Gulu, Uganda. ${ }^{3}$ Department of Medicine, Makerere University College of Health Sciences, P.O Box 7072, Kampala, Uganda.

Received: 16 October 2014 Accepted: 18 March 2015

Published online: 31 March 2015

\section{References}

1. Kalyesubula R, Perazella MA. Nephrotoxicity of HAART. AIDS Res Treat. 2011;2011:562790.

2. Crowley S, Rigsby M. The spectrum of HIV-associated renal disease. AIDS Clin Care. 1996;8(7):53-6.

3. Arendse CG, Wearne N, Okpechi IG, Swanepoel CR. The acute, the chronic and the news of HIV-related renal disease in Africa. Kidney Int. 2010;78(3):239-45.

4. Connolly JO, Weston CE, Hendry BM. HIV-associated renal disease in London hospitals. QJM. 1995;88(9):627-34.

5. Calza L, Vanino E, Magistrelli E, Salvadori C, Cascavilla A, Colangeli V, et al. Prevalence of renal disease within an urban HIV-infected cohort in northern Italy. Clin Exp Nephrol. 2014;18(1):104-12.

6. Ekat MH, Courpotin C, Diafouka M, Akolbout M, Mahambou-Nsonde D, Bitsindou PR, et al. [Prevalence and factors associated with renal disease among patients with newly diagnoses of HIV in Brazzaville, Republic of Congo]. Med et sante tropicales. 2013;23(2):176-80. Epub 2013/06/22. Prevalence et facteurs associes a l'insuffisance renale chez les patients nouvellement depistes VIH-positifs a Brazzaville (Republique du Congo).

7. Gupta V, Gupta S, Sinha S, Sharma SK, Dinda AK, Agarwal SK, et al. HIV associated renal disease: a pilot study from north India. Indian J Med Res. 2013;137(5):950-6.

8. Emem CP, Arogundade F, Sanusi A, Adelusola K, Wokoma F, Akinsola A. Renal disease in HIV-seropositive patients in Nigeria: an assessment of prevalence, clinical features and risk factors. Eur Renal Assoc. 2008;23(2):741-6.

9. Fine DM. Renal disease and toxicities: issues for HIV care providers. Topics HIV Med. 2006;14(5):164-9.

10. Szczech LA, Hoover DR, Feldman JG, Cohen MH, Gange SJ, Gooze L, et al. Association between renal disease and outcomes among HIV-infected women receiving or not receiving antiretroviral therapy. Clin Infec Dis. 2004;39(8):1199-206.

11. Szczech LA. Renal disease: the effects of HIV and antiretroviral therapy and the implications for early antiretroviral therapy initiation. Curr Opin HIV AIDS. 2009;4(3):167-70.
12. Bohmart $A$, Burns $G$. Renal disease in an urban HIV population in the era prior and following the introduction of highly active antiretroviral therapy. J Natl Med Assoc. 2011;103(6):513-7.

13. Levey AS, Stevens LA, Schmid CH, Zhang YL, Castro 3rd AF, Feldman HI, et al. A new equation to estimate glomerular filtration rate. Ann Intern Med. 2009;150(9):604-12.

14. National Kidney Foundation. KDOQI clinical practice guidelines for chronic kidney disease: evaluation, classification, and stratification. Am J Kidney Dis. 2002;39(39(2 suppl 1)):S1-266.

15. Franey C, Knott D, Barnighausen T, Dedicoat M, Adam A, Lessells RJ, et al. Renal impairment in a rural African antiretroviral programme. BMC Infect Dis. 2009;9:143.

16. Simerville JA, Maxted WC, Pahira JJ. Urinalysis: a comprehensive review. Am Fam Physician. 2005;71:1153-62.

17. Mulenga LB, Kruse G, Lakhi S, Cantrell RA, Reid SE, Zulu I, et al. Baseline renal insufficiency and risk of death among HIV-infected adults on antiretroviral therapy in Lusaka, Zambia. AIDS. 2008;22:1821-7.

18. Onodugo OD, Chukwuka C, Onyedum C, Ejim E, Mbah A, Nkwo P, et al. Baseline Renal Function among Antiretroviral Therapy-Naive, HIV-Infected Patients in South East Nigeria. J Int Assoc Providers AIDS Care. 2013;00:1-5.

19. Kaloustian KW, Gupta SK, Muloma E, Owino-Ong'or W, Sidle J, Aubrey RW, et al. Renal disease in an antiretroviral-nai ve HIV-infected outpatient population in Western Kenya. Nephrol Dial Transplant. 2007;22:2208-12.

20. Wyatt CM, Shi Q, Novak JE, Hoover DR, Szczech L, Mugabo JS, et al. Prevalence of Kidney Disease in HIV-Infected and Uninfected Rwandan Women. PLoS One. 2011;6(3):e18352. Doi 10.1371/journal.pone.0018352.

21. Ekat E, Diafouka D. Renal dysfunction and factors associated among newly identified HIV-infected patients in Brazzaville, Republic of Congo. J Int AIDS Soc. 2012;15 Suppl 4:18313.

22. Zachariah R, Fitzgerald M, Massaquoi M, Pasulani O, Arnould L, Makombe S, et al. Risk factors for high early mortality in patients on antiretroviral treatment in a rural district of Malawi. AIDS. 2006;20(18):2355-60.

23. Struik GM, den Exter RA, Munthali C, Chipeta D, Van Oosterhout JJ, Nouwen $\mathrm{JL}$, et al. The prevalence of renal impairment among adults with early HIV disease in Blantyre, Malawi. Int J STD AIDS. 2011;22:457-62.

24. Janakiraman H, Abraham G, Matthew M, Kuruvilla S, Panikar V, Solomon S, et al. Correlation of CD4 Counts with Renal Disease in HIV Positive Patients. Saudi J Kidney Dis Transpl. 2008;19:603-7.

25. Chioma PE, Arogundade F, Sanusi A, Kayode A, Wokoma F, Akinsola A. Renal disease in HIV-seropositive patients in Nigeria: an assessment of prevalence, clinical features and risk factors. Nephrol Dial Transplant. 2008;23:741-6.

26. Longo AL, Lepira FB, Sumaili EK, Makulo JRR, Mukumbi H, Bukabau JB, et al. Prevalence of Low Estimated Glomerular Filtration Rate, Proteinuria, and Associated Risk Factors Among HIV-Infected Black Patients Using CockroftGault and Modification of Diet in Renal Disease Study Equations. J Acquir Immune Defic Syndr. 2012;59(1):59-64.

27. Peters PJ, Moore D, Mermin J, Brooks JT, Downing R, Were W, et al. Renal function improves among Ugandans on NNRTI-based HAART: 24 month follow-up from the Home-Based AIDS Care (HBAC) program in rural Uganda. Los Angeles: Conference on Retroviruses and Opportunistic Infections; 2007.

28. Fabian J, Naicker S. HIV and kidney disease in sub-Saharan Africa. Nat Rev Nephrol. 2009:5(10):591-8.

29. Reid A, Stohr W, Walker AS, Williams IG, Kityo C, Hughes P, et al. Severe renal dysfunction and risk factors associated with renal impairment in HIVinfected adults in Africa initiating antiretroviral therapy. Clin Infect Dis. 2008:46:1271-81.

30. Szczech LA, Gupta SK, Habash R, Guasch A, Kalayjian R, Appel R, et al. The clinical epidemiology and course of the spectrum of renal diseases associated with HIV infection. Kidney Int. 2004;66(3):1145-52.

31. Mauss S, Berger F, Schmutz G. Antiretroviral therapy with tenofovir is associated with mild renal dysfunction. AIDS. 2005;19(1):93-5.

32. Julg BD, Bogner JR, Crispin A, Goebel FD. Progression of renal impairment under therapy with tenofovir. AIDS. 2005;19:1332-3. 